\title{
Study of epidemiological characters, predisposing factors and treatment outcome of corneal ulcer patients
}

\author{
Khare $\mathbf{P}^{1}$, Shrivastava $\mathbf{M}^{2}$, Kumar $\mathbf{K}^{3}$ \\ ${ }^{1}$ Dr Praveen Khare, Assistant Professor, Department of Ophthalmology, ${ }^{2}$ Prof Meeta Shrivastava, Professor and Head, \\ Department of Opthalmology. Both affiliated with Bundelkhand Medical College Sagar,Madhya Pradesh, India. ${ }^{3}$ Dr Kavita \\ Kumar, Associate professor, Department of ophthalmology, Gandhi Medical College Bhopal, Madhya Pradesh, India
}

Address for correspondance: Dr Praveen Khare, E-mail-praveenkhare_77@rediffmail.com

\begin{abstract}
Introduction: Corneal ulcer is one of the common reasons for ophthalmic OPD and IPD visit. It is responsible for vision loss in large number of patients. We have conducted this study to evaluate epidemiological characteristics, predisposing factors and treatment outcome of corneal ulcer patients in tertiary care teaching hospital. Method: A prospective study of corneal ulcer patients from Dec 2009 to Nov 2013 was done. Data related to socio-demography, predisposing factors, prior treatment and duration of symptoms were recorded. Ulcer was evaluated by slit lamp examination. Corneal scrapings were subjected to Gram`s stain and 10\% KOH wet mount. Results: 432 eyes were evaluated. $53.9 \%$ were between $26-45$ yrs.71.06\% eyes presented with vision $<3 / 60$. Trauma was commonest factor found in $53.93 \%$ patients. On staining $22.9 \%$ were having fungal and $64.12 \%$ mixed bacterial and fungal infection. Anatomically $34.7 \%$ completely recovered leaving scar. 3 eyes were eviscerated, rest not completed treatment. Conclusion: Corneal ulcer is common eye problem in developing countries. Most of ulcers were moderate to severe grade. Treatment given on the basis of basic laboratory investigations and clinical features was effective in about $84 \%$ of patients. Severe consequences can be prevented by community based awareness.
\end{abstract}

Keywords - corneal ulcer, evisceration, fungal,scraping, snellen acuity, staining

\section{Introduction}

Corneal infection is a major public health problem worldwide \& most common cause of monocular corneal blindness. $^{1}$ The incidence of ulcerative keratitis varies from 11 per $100000 / y r$ in $\mathrm{USA}^{2}$ to 799 per $100000 / \mathrm{yr}$ in developing countries. ${ }^{3}$ Condition is even worse in developing countries not only due to high incidences but also due to late presentation to an ophthalmologist. Availability of investigations like microbiological evaluation and culture sensitivity, necessary for proper management is limited in rural areas. Early diagnosis \& rational therapy reduces the dreaded complications of ulcer. Most patients belong to rural areas in developing countries, as agriculture trauma is a leading cause of ulcer. Lack of knowledge of proper use of steroids makes condition even worse.

Purpose of this study is to evaluate the efficacy of management of ulcer on the basis of clinical features and corneal scraping results. It will help medical and

\footnotetext{
Manuscript received: $14^{\text {th }}$ Dec 2013

Reviewed: $29^{\text {th }}$ Dec 2013

Author Corrected: $25^{\text {th }}$ Jan 2014

Accepted for Publication: 29 ${ }^{\text {th }}$ Jan 2014
}

paramedical staff working at rural places to treat ulcer more effectively. Bundelkhand Medical College is situated in central part of Madhya Pradesh serving large rural population surrounding Sagar division and adjacent areas. Most of the patients are from rural areas. In the present study, we have highlighted the demographic pattern, predisposing factors, and status of ulcer at the time of presentation with result of management in uncomplicated cases on the basis of basic laboratory investigation and clinical findings.

\section{Material and Methods}

This study was conducted in ophthalmology department of Budelkhand Medical College Sagar from December 2009 to November 2013. During these four years about 80,000 patients were seen in our department out of which 693 were recorded ulcer patients. We included 432 eyes of 432 patients in our study. Patients with presumed microbial keratitis were included in this study with exclusion criteria of

1. Those with viral keratits

2. Ulcer with impending or actual perforation

3. Ulcer with near total corneal melting 
4. Ulcer in healing stage with prior treatment

5. Patients not certain of regular follow up

6. Small children in whom proper examination and scraping was not possible without GA.

Study was conducted with the approval of hospital management. Data related to socio demographic features were recorded. History was taken to find out predisposing factors, previous treatment, and duration of symptoms. Presenting visual acuity was recorded at the time of presentation. Patients were evaluated on slit lamp biomicroscope to record size, depth and location of ulcer along with examination of margins, floor and infiltrations. Presence or absence of hypopyon was noted. Examination of ocular adenexa including lids, eyelashes and lacrimal sac area was done. Patency of lacrimal system was checked by syringing. Blood sugar was done to screen diabetes mellitus in every patient.

The scraping of corneal ulcer was then performed and subjected to Gram's stain and $10 \% \mathrm{KOH}$ wet mount to identify fungus or bacteria. ${ }^{5}$ Pre disposing factors if more than one were included separately. Ulcer was graded as per our criteria in to mild, moderate $\&$ severe form. ${ }^{6}$

The therapy was started on the basis of clinical examination \& laboratory staining results. For suspected bacterial ulcer, therapy given was ciprofloxacin $0.3 \%$ eye drop alone. Combination of fortified cefazoline $5 \%$ \& gentamicin $1.4 \%$ was given in non-responding cases. Oral Ciprofloxacin was added in patients with ulcer near limbus. In the fungal corneal ulcers initial therapy was Natamycin 5\% eye drop alone, in ulcers not more than $50 \%$ of corneal thickness. Oral ketoconazole tablets 3.3$6.6 \mathrm{mg} / \mathrm{kg}$ body weight daily were added if deeper infection was present. Fluconazole eye drops were added in to the therapy in non responding cases. Combination therapy including both antibacterial and antifungal were given in ulcers with suspected mixed infection, either clinically or on scrapings.

Patients were seen again after 48 hours \& response was evaluated on the basis of signs of inflammation \& symptomatic relief to the patient. Atropine $1 \%$ eye drop three-time daily was given in all patients as supportive therapy. Systemic carbonic anhydrase inhibitor (Acetazolamide) $1.5 \mathrm{mg} / \mathrm{kg}$ body weight was given to the patients with ulcer extending to the limbus or those in which secondary glaucoma was suspected.

Patients showing improvements were reevaluated after seven days $\&$ those who were not showing improvement were admitted to see compliance, re-scraping was done $\&$ therapy modified accordingly. Those who came with perforation or impending perforation were treated either by cyanoacylate glue application or tarsorrhaphy or conjunctival grafting as per indication. We had to eviscerate 3 eyes because of severe progression of ulcer.

First follow up in our study means follow up after one week of initiation of therapy \& second follow up was in 2-3 weeks. Status of ulcer was evaluated on each follow up, on the basis of clinical features as whether healing or deteriorated. Visual acuity was recorded \& change in visual acuity was noted.

Patients were kept on follow up till complete resolution of ulcer. Antimicrobials were prescribed four times a day after complete healing for one week in bacterial and for two weeks in fungal corneal ulcer to prevent recurrences.

Treatment was considered as successful if final outcome was an inactive corneal opacity and was recorded as complete recovery. Patients, in whom anatomical integrity couldn't be saved, like those who were eviscerated or perforated, were categorized as deteriorated.

\section{Results}

$234(54.2 \%)$ patients presenting to our hospital were male with male female ratio of 1.18 .

Table No 1: Distribution of patients according to age

\begin{tabular}{|l|l|}
\hline Age group of the patient & No. of patients \\
\hline$<15$ yrs & 18 \\
\hline $16-2516$ yrs & 50 \\
\hline $26-35$ yrs & 123 \\
\hline $36-45$ yrs & 110 \\
\hline $46-55$ yrs & 74 \\
\hline $56-65$ yrs & 41 \\
\hline$>65$ yrs & 16 \\
\hline
\end{tabular}

As per the table depicted $233(53.9 \%)$ patients were in between 26 to 45 years of age. Only 18(4.16\%) patients were of pediatric age group $(<15$ years $)$. 
$307(71.06 \%)$ eyes were blind $(<3 / 60)$ at the time of presentation \& $19(4.39 \%)$ had visual acuity more than or equal to $6 / 18$. (Figure 1)

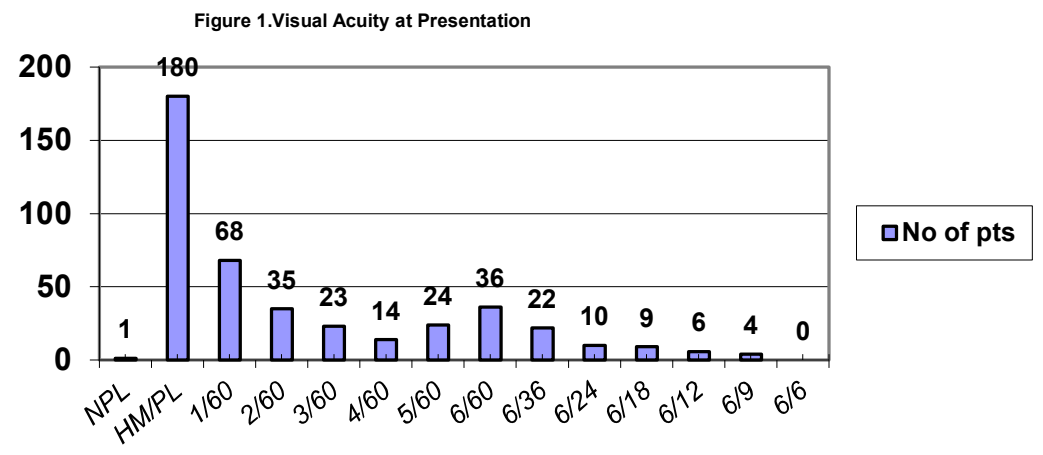

Trauma was the most common predisposing factor, found in $233(53.93 \%)$ patients but cause was not identified in $188(43.51 \%)$

Table No 2: Location and size of Ulcer

\begin{tabular}{|c|c|c|c|}
\hline Location Of Ulcer & No. of patients & Size of Ulcer & No of Patients \\
\hline Central & 90 & $<2 \mathrm{~mm}$ & 22 \\
\hline Paracentral & 57 & $2-5 \mathrm{~mm}$ & 322 \\
\hline Peripheral & 09 & $>5 \mathrm{~mm}$ & 88 \\
\hline Central+ Paracentral & 182 & & \\
\hline Central+ Paracentral+ Pericenrtal & 76 & & \\
\hline Paracentral+Pericentral & 18 & & \\
\hline
\end{tabular}

On slit lamp biomicroscopy, ulcers were found to be in central \& Para central region of cornea in $329(76.15 \%)$ patients while in $9(2.1 \%)$ patients only peripheral part was involved. In $76(17.6 \%)$ cases ulcer was large enough to involve central, Paracentral and peripheral part. $322(74.53 \%)$ ulcers were of size $2-5 \mathrm{~mm}, 88(20.37 \%)$ were of size $>5 \mathrm{~mm}$ and only $22(5.1 \%)$ patients were mild type involving $<2 \mathrm{~mm}$ of cornea (Table N0.2)

Table No 3: Depth of Ulcer and Microbial agent

\begin{tabular}{|c|c|c|c|}
\hline Depth of Ulcer & No. of Patients & Microbial agent & \\
\hline$<20 \%$ of corneal thickness & 1 & Fungal & $99(22.91 \%)$ \\
\hline $20-50 \%$ & 352 & mixed & $277(64.12 \%)$ \\
\hline$>50 \%$ & 79 & bacterial & $36(8.3 \%)$ \\
\hline
\end{tabular}

$79(18.28 \%)$ ulcers were involving more than $50 \%$ of corneal thickness, 352(81.48\%) involving superficial stroma \& only 1was epithelial ulcer. On corneal scraping, 99 (22.91\%) were pure fungal ulcers \& $277(64.12 \%)$ were fungal ulcers having co-infection with bacteria while only bacteria was identified in $36(8.3 \%)$ patients. (Table 3 )

Table No 4: Status of Ulcer on follow-up

\begin{tabular}{|c|c|c|}
\hline Status of Ulcer & First follow-up & Second follow-up \\
\hline Healing & 281 & 195 \\
\hline No change & 48 & 16 \\
\hline Progressed & 8 & 14 \\
\hline Perforated & 2 & 10 \\
\hline No follow-up & 93 & 104 \\
\hline
\end{tabular}

$339(78.47 \%)$ patients came for $1^{\text {st }}$ follow up. $281(82.9 \%)$ were in healing stage. $10(2.94 \%)$ were deteriorating out of which 2 cases i.e. $0.59 \%$ were perforated. 
Table No 5: Change in visual acuity on follow-up

\begin{tabular}{|c|c|c|}
\hline Change in visual acuity & First follow-up & Second follow-up \\
\hline Improved & 118 & 155 \\
\hline Deteriorated & 17 & 52 \\
\hline No change & 204 & 104 \\
\hline No follow-up & 93 & 28 \\
\hline
\end{tabular}

118(34.8\%) had shown improvement on snellen acuity, while 17(5.01\%) patient's visual acuity decreased compared to their acuity at the time of presentation. In rest of the 204(47.22\%) patients there was no change in visual acuity.

Out of 339 patients who came for $1^{\text {st }}$ follow up, $235(69.3 \%)$ came for subsequent follow-ups. In these patients $195(82.97 \%)$ were healing and $24(10.2 \%)$ were deteriorating clinically in which $10(4.2 \%)$ were perforated.

Anatomically, 150(34.7\%) patients recovered completely leaving a corneal scar only. $3(0.6 \%)$ eyes were eviscerated. Rest of the patients stopped follow ups before completion of treatment.

\section{Discussion}

Infective keratitis is a major public health problem in developing countries. ${ }^{7,8}$ If not diagnosed early and treated effectively may lead to loss of not only sight but even eye too. The spectrum of corneal ulcer presentation worldwide has large variations \& this is especially due to difference in geographical \& socio economic structures. Occurrence of corneal ulcer is significantly associated with lower socio economic status. ${ }^{9}$

Highest number of patients presenting to our hospital were between 26 to 45 years of age.

This is socio economically active age group. Morbidity of these people affects whole of the family. Most of them are agriculture worker as this is the commonest occupation of rural population in developing countries. This explains why agriculture trauma is the leading predisposing factor of corneal ulcer in developing countries. ${ }^{10}$

This is in concurrence with that of Panda et $a l^{10}$ and other studies $^{3,4,11}$ where non-surgical trauma is found to be the leading cause of corneal ulcer. We had $43.5 \%$ patients in which cause was unidentified. This is a large number and certainly needs improvement in our work-up system.

Schaefer et al have identified co existing ocular diseases as a major pre disposing factor ${ }^{12}$ but in our study only one percent ulcers had concurrent ocular diseases. Bourcier et al found contact lenses as major risk factor, which is less in this part of world. ${ }^{13}$

Male preponderance is 1.18 that of female. Male predominance is found in many studies ${ }^{4,14}$, some has found it in ratio as high as 1.6. This may be because males are more involved in outdoor activities and also males are preferred over females to seek medical advice.
Most of the ulcer presenting to us are of severe grade and late presentation is mainly responsible for this. Majority of patients coming to our hospital are from nearby rural places. Most of them take initial treatment from local practitioner including paramedical and medical personnel, relatives, traditional healer and even directly from drug stores. Patient's accessibility to eye care services is the main barrier for early consultation followed by cost, social belief, and ignorance about the disease. $23.8 \%$ patients were on steroid therapy at initial presentation. Topical steroids could have suppressed the inflammation so that patient might have been less symptomatic ${ }^{15} \&$ thus presenting late to the ophthalmologist. Steroids also predispose to fungal keratitis. More than $2 / 3$ rd of the patients had vision $<3 / 60$ in affected eye at initial presentation. Similar results were noted in other studies ${ }^{10}$

Large numbers of fungal infection were found in our hospital, which was higher than that found in other studies. ${ }^{4,16,17}$ Agriculture trauma is responsible in our study. Similar results are also seen in other studies ${ }^{3,4,11}$. Many of the patients were using either corticosteroid $(23.8 \%)$ or some unidentified drops $(40.3 \%)$ before coming to this hospital and association of fungal keratitis with use of corticosteroid and diabetes mellitus has been reported earlier. ${ }^{18,19}$

Percentage of mixed bacterial and fungal infection is also high. About $65 \%$ of fungal infections are having coinfection with the bacteria. Recent studies found bacteria in $5 \%$ to $25 \%$ of keratomycosis. ${ }^{4,} 20-23$ But other laboratories in Asia and South America have isolated bacteria in approximately $30 \%$ to $60 \%$ of corneal specimen during fungal keratities. ${ }^{3}, 24,25$ This diverse prevalence estimate may indicate non-conformity in distinguishing microbial co-infection, and dual infections, 
but could be due to differences in risk factors, climate $\&$ access to care also. The detection of fungal filaments in $10 \% \mathrm{KOH}$ mount has $90-99 \%$ sensitivity. ${ }^{16}, 26$ While sensitivity \& specificity of bacterial detection in Gram's stain is inferior to that of culture method. ${ }^{27}$ Senstivity of Gram stain in detection of bacteria was $36.0 \%$ in early and $40.9 \%$ in advanced keratitis cases ,however specificity is higher $(84.9 \%$ and $87.1 \%$ respectively $) .{ }^{5}$ This could also be a reason for less bacterial detection in our series.

Microbiological work-up is now recommended in all suspected cases of microbial keratitis and its importance is proved in many studies, but most general ophthalmologist do not practice the recommendations. ${ }^{28}$ In a study only $10 \%$ ophthalmologist were found to have the facility of Gram stain and only $14.5 \%$ of all ulcers were examined with scraping for Gram stain and culture. ${ }^{28}$ A survey in United States had revealed that commonly practitioners start empirical treatment with antimicrobials for ulcers and microbiological evaluation is done only in nonresponding cases. ${ }^{28}$

This practice can be applied if bacterial infection is the dominating cause of ulcer but places like India and other countries where fungal ulcers are more common ${ }^{4,16,17}$ this approach is not recommended. Jones DB's suggestions of initial therapeutic treatment on the basis of corneal smear, clinical features and severity of keratitis ${ }^{29}$ are very much applicable in areas with high prevalence of fungal corneal infections.

To grade the ulcer prior to its management is an important parameter, as severe ulcer requires closer observation. $20.4 \%$ ulcers were more than $5 \mathrm{~mm}$ size and, $18.3 \%$ were having ulcer of depth more than $50 \%$. $76 \%$ of ulcer were involving central part of cornea. Other studies ${ }^{10}$ have found a large percentage of severe grades of ulcer.

Treatment was given as Netamycin ${ }^{30}$ drops \& systemic ketoconazole in deeper penetration of suspected fungal corneal ulcers. Suspected bacterial ulcers were treated with either ciprofloxacin eye drops or combination fortified cefazoline $\&$ gentamicin eye drops ${ }^{31-33}$

We had 12 perforations during our study, reasons could be poor patient compliance or resistant cases, but possibility of prolong use of topical fluoroquinolones being responsible for this hazard cannot be ruled out and causes other then fungal and bacteria can also be responsible for non healing ulcers

Major limitation of this study is that we had to exclude large number of patients attending the OPD. About $40 \%$ of total ulcer patients were excluded. Follow up rate was also not encouraging as only $2 / 3$ rd patients came for follow-up, but $82 \%$ follow up were clinically in healing stage. Though $34.1 \%$ were still with poor vision but $65.9 \%$ had improvement in snellen's acuity. Less follow up may be because most patients coming to our hospital are poor and coming from far places. That's why only $35.4 \%$ had actually completed the therapy; rest had stopped follow-ups before completion of therapy.

\section{Conclusion}

In summary our study highlights that corneal ulcer in this part of the world is a major eye problem. Incidence can be reduced, if the predisposing factors can be controlled ${ }^{34}$. If treatment starts at early stage then basic laboratory investigations \& knowledge of clinical features is very helpful in effective management of corneal ulcers.

Topical fluoroquinolones \& Natamycin supported with fortified cefazoline \& gentamicin \& Fluconazole are effective in uncomplicated cases. So the prevention of predisposing factors, appropriated diagnosis at early stage \& proper medical management can help greatly in handling microbial keratitis properly.

Local paramedical and medical people if trained to manage ulcer with the use of this knowledge than we can manage them effectively at an early stage. A community based awareness program regarding risk factors like trauma to eye and use of medications without proper prescription may create a difference in over all scenario of ulcer presentation.

\section{Funding: Nil}

Conflict of interest: Nil

\section{Permission from IRB: Yes}

\section{References}

1. Chirambo MC, Tielsch JM, West KP,Katz J. Blindness and visual impairment in southern malwai. WHO bull 1986; 64(4); 576-82.

2. Erie JC, Nevitt MP, Hodge DO, Ballard DJ. Incidence of ulcerative keratitis in a defined population from 1950 through 1988. Arch ophthalmol 1993, 111(12); 1665-71.

3. Upadhyay M, Karmacharya PC, Koirala S, Shah DN, Shakya S, Shrestha JK, Bajracharya H, Gurung CK,WHitcher JP. The Bhaktapur eye study: ocular trauma and antibiotic prophylaxis for prevention of corneal ulceration in Nepal. $\mathrm{Br} \mathrm{J}$ Ophthalmol 2001;85(4);388-92.

Available online at: www.ijmrr.in

37 | P a g e 
4. Srinivasan M, Gonzales CA, George C, Cevallos V, Mascarenhas JM, Asokan B. Epidemiology \& aetiological diagnosis of corneal ulceration in madurai. Br J ophthalmol 1997; 81(11):965-71.

5. Sharma S, Kunimoto DY, Gopinathan U, Athmanathan S, Garg P, Rao GN.Evaluation of corneal scraping smear examination methods in diagnosis of bacterial and fungal keratitis :A survey of eight year of laboratory experience.

Cornea 2002;21(7):643-7.

6. Gregory S,Ogawa \& Rober A, Hyndiuk in "The Cornea" by Smolin \& Theoft, $3^{\text {rd }}$ edition; 128

7. Bharathi M, Ramakrishnan R, Vasu S. Epidemiology of bacterial keratitis in a referral centre in south India. Indian J Ophthalmol. 2003;21(4):239-245.

8. Goonawardana S, Ranasinghe K, Arseculeretnae S, et al. Survey of mycotic and bacterial keratitis in Sri Lanka. Mycopathologia 1994; 127:77-81

9. Vajpayee RB, Ray M, Panda A, Sharma N,Taylor HR,Murthy GV,Satpathy G,Pandey RM.Risk factors for paediatric presumed microbial keratitis: a case control study. Cornea 1999;18(5):565-9.

10. Panda A,Satpathy G,Nayak N,Kumar S,Kumar A.Demographic pattern, predisposing factors and management of ulcerative keratitis:evaluation of thousand cases at a tertiary care centre.Clinical and experimental ophthalmol 2007;35(1):44-49.

11. Thylefors B. Epidemiological pattern of ocular of ocular trauma.Aust NZ J ophthalmol 1992(2); 20:9598

12. Schaefer F,Bruttin O,Zografos L,Guex-Crosier Y. Bacterial keratitis:A prospective clinical and microbiological study.Br J Ophthalmol 2001;85:84247.

13. Boucier T,Thomas F,Borderie V,Chaumeil C,Laroche L. Bacterial Keratitis :Predisposing factors, clinical and

Microbiological review of 300 cases.Br J Ophthalmol 2003; 87(7):430-6.

14. Gonxales CA, Srinivasan M, Whitcher JP, Smolin G. Incidence of corneal ulceration in maduari. Ophalmic epidemiol 1996; 3(3):159-66.
15. Wilhelmus KR. Indecision about corticosteroids for bacterial keratitis; an evidence-based update. Ophthalmology 2002; 109(5):835-42.

16. Bharathi M, Ramakrishnan R,Vasu S,Meenakshi R,Palaniappan R.Epidemiological characteristics and laboratory diagnosis of fungal keratitis: A three year study 2003; IJO : 51(4), 315-321.

17. Chander J ,Sharma A.Prevalence of fungal corneal ulcer in northern India. Infection1994; 22(3):207-209.

18. Gopinathan U ,Garg P,Fernandes M,Sharma S,Atmanathan S,Rao GN.The epidemiological features and laboratory results of fungal keratitis: a ten year review in a referral eye care centre in south India.Cornea 2002;21(6) :555-59.

19. Agrawal PK, Roy P,Das A,Banerjee A,Maity PK,Banerjee AR;Efficacy of systemic and topical Itraconazole as a broad spectrum anti fungal agent in mycotic corneal ulcer.A preliminary study.Indian J Ophthalmol. 2001; 49(3):173-76.

20. Leck AK, Thomas PA,Hagan M,Kaliamurthy J,Ackuaku E,John M, et al.Etiology of suppurative corneal ulcer in Ghana and South India,and epidemiology of fungal keratitis. $\mathrm{Br} \quad \mathrm{J}$ Ophthalmol2002;88(11):1211-15.

21. Satpathy G, Vishalakshi P.Ulcerative keratitis: Microbial profile and sensitivity pattern-a five year study. Ann Ophthalmol1995:27;301-6.

22. Basak SK,Bask S, Mohanta A,Bhowmick A. Epidemiological and microbiological diagnosis of suppurative keratitis in Gangetic West Bengal, eastern India.Indian J ophthalmol 2005:53(1);17-22.

23. Choudhary A, Singh K.Spectrum of fungal keratitis in northern India.Cornea 2005:24(1);8-15.

24. Laspina F,Samudio M,Cibils D,TaCN,Farina N,Sanabria R,Klauss V,Mino de Kaspar H. Epidemiological Characteristic of microbiological results on patients with infectious corneal ulcer: a 13years survey in Paraguay;Grafes Arch clin exp ophthalmol2004;242 (3) :204-9.

25. Khanal B,Deb M,Panda A,Sethi HS.Laboratory diagnosis in ulcerative keratitis; Ophthalmic Ref 2005; 37(3):123-7. 
26. Vajpayee RB,Angra SK,Sandramouli S,Honavar SG,Chhabra VK.Laboratory diagnosis of keratomycosis: Comparative evaluation of direct Microscopy and culture results. Ann Ophthalmol 1993;25(2):68-71

27. Wahl J, Katz, H and Abrams D. Infectious Keratits in Baltimore.AnnOphthalmol,23(6):234,1991.

28. McDonell P,Nobel J,Gauderman W,Lee P,Aiello A,Trousdale M.Community care of corneal ulcers. Am J Ophthalmol 1992;114(5):531-8.

29. Jones DB. Decision-making in the Management of microbial keratitis.Ophthalmology1981; 88(8):814-20

30. O’Day D. Selection of appropriate antifungal therapy. Cornea 1987:6(4); 238-45.

31. O` BrienTP,Maguire MG,Fink NE,Alfonso E,Mc DonnellP.Efficacy of Ofloxacin vs Cefazoline and tobramycin in the therapy of bacterial keratitis report from the bacterial keratitis study group. Arch Ophthalmol. 1995; 113(10):1257-1265.

32. Prajna NV,George C,Selvaraj S,Lu KL,McDonnell PJ,Srinivasan M. Bacteriological and clinical efficacy, Ofloxacin $0.3 \%$ versus Ciprofloxacin $0.3 \%$ ophthalmic solution in treatment of patients with culture positive Bacterial keratitis. Cornea 2001:20(2); 175-8.

33. Morlet N,Daniell M.Microbial keratitis:What the preferred initial therapy? View- 2: Empirical fluoroquinolone therapy is sufficient initial treatment.Br J Ophthalmol 2003:87(9);1169-72.

34. Getshen K, Srinivasan M, Upadhyay M, Priyadarsini B, Mahalaksmi R, Whitcher JP. Corneal ulceration in South East asia. a model for the prevention of bacterial ulcers at the village level in rural Bhutan. $\mathrm{Br}$ J Ophthalmol 2006; 90(3):276-8.

\section{How to cite this article?}

Khare P, Shrivastava M, Kumar K. Study of epidemiological characters, predisposing factors and treatment outcome of corneal ulcer patients. Int J Med Res Rev 2014;2(1):33-39, 10.17511/ijmrr.2014.i01.07 